\title{
7th International Conference on Ion Implantation Technology Held in Kyoto
}

The 7th International Conference on Ion Implantation Technology (IT'88) was held June 7-10, 1988 at the Kyoto International Conference Hall, Kyoto, Japan. Over 450 participants from 22 countries attended. A total of 253 oral and poster papers were presented during seven technical sessions and a plenary session. Five plenary overviews and 52 invited talks, including several keynote papers at each technical session, covered the conference's topical themes.

The scope of the Kyoto conference was especially broad, including a wide coverage of ion beam technologies from ion beam deposition in the low energy range (eV) to very high energy implantation (MeV). Also included were the traditional conference topics of process requirements and the design and performance of ion implantation equipment.

Several other activities accompanied the conference's technical sessions. As a section of the IIT' 88 , the Workshop on Characterization of Implantation in Silicon was held on June 2-3, 1988 in Shanghai, China. [See summary in the September MRS BULLETIN, p. 34.] A two-day school on Ion Implantation-Science and Technology was held before the conference (June 5-6), and an equipment exhibition was held during the conference. The equipment exhibition gave participants practical information on ion implantation and related technologies in addition to business information.

IIT'88 chairman Prof. T. Takagi previewed the scope of the conference in his opening address entitled "A Perspective of eV-MeV Ion Beams." Four plenary talks followed: "Current Status of Ion Implantation for VLSI Application" by Y. Akasaka of Mitsubishi Electric Corp., "Ion Beam Deposition in Materials Research" by B.R. Appleton of Oak Ridge National Laboratory, "Materials Modification with Ion Beams" by J.W. Mayer of Comell University, and "Advanced Ion Beam Equipment used for Semiconductor Production" by P.H. Rose of Eaton Corporation. After these talks, seven technical areas, described briefly below, were covered in three parallel sessions.

\section{Ion Sources}

Positive and negative ion sources, very low energy ion sources, and large diameter ion sources were major topics. Because of their simplicity of construction, Freemantype ion sources are still widely used for medium and high current ion implanta- tion equipment. N.R. White (Applied Materials, formerly Genus/Ionex Corp.) capably reviewed this subject. K. Amemiya (Hitachi) spoke about microwavetype ion sources. This type of ion source is especially interesting because the source has no heater and could be used for $\mathrm{MeV}$ implantation by extracting $\mathrm{mA}$ order currents and high charge state ions. J. Ishikawa (Kyoto University) discussed high-intensity negative-ion sources with currents of a few hundred microamps. G. Proudfoot (Culham Laboratory) discussed a very low energy ion source. The beam energy is variable from $80 \mathrm{eV}$ to several hundreds of $\mathrm{eV}$ with total extracted beam currents up to $400 \mathrm{~mA}$.

$H$. Kaufman, originator of the Kaufmantype ion source, described a $38 \mathrm{~cm}$ large diameter ion source and its applications to etching processes in semiconductor fabrication. K.H. Leung (Lawrence Berkeley Laboratory), G.D. Alton (Oak Ridge National Laboratory), and N. Bacal (Ecole Polytechnique) reported on significant recent developments in several types of negative ion sources, including physics research applications. Metal ion sources are important for extending ion implantation technologies into materials science. I.G. Brown (Lawrence Berkeley Laboratory) gave an interesting invited talk on ECR (electron cyclotron resonance) and MEVVA (metal vapor vacuum arc) ion sources. These sources are available to obtain metallic ion species spanning the periodic table from lithium to uranium.

\section{Ion Beam Transport}

Finely focused ion beams, low energy ion beam extraction, and high energy and high current rf accelerators were major topics. R. Aihara (JEOL), T. Kato (Mitsubishi), and $A$. Wagner (IBM) gave invited talks on finely focused ion beams. Aihara detailed the characteristics of focused ion beam systems. In the JIBL-200S, the reported stitching accuracy and overlay accuracy are $0.2 \mu \mathrm{m}$ and $0.25 \mu \mathrm{m}$, respectively. Kato described the fabrication of a GaAs FET with a mushroom gate structure by focused ion beam lithography, and of a low noise and high gain GaAs HEMT by $\mathrm{Be}^{+2}$ and $\mathrm{Si}^{+2}$ implantation processes. P.D. Reader (Ion Tech Inc.) reviewed the development of low energy sources with extraction under a few hundred volts with large diameter. His paper was extremely relevant to technologies for both direct and enhanced ion beam deposition processes.

\section{Ion Implantation and Ion Beam Interactions with Solids}

Participants in this session discussed the fundamentals of ion implantation, ionbeam spectrometries, and the application of ion implantation to semiconductor device fabrication. Evaluations of implantation damage, epitaxial processes, and diffusion were treated. W.L. Brown (Bell Laboratories) covered recent important developments in ion implantation processes in semiconductors and molecular solids. T.W. Sigmon (Stanford University) discussed solid phase epitaxial processes in heavily damaged semiconductors. $M$. Aono (Riken) and Wei-Kan Chu (University of North Carolina) reported different methods of ion beam spectrometry using a low energy scattering method and a scattering recoil coincidence method, respectively. Pulsed ion implantation in metals and semiconductors may extend ion beam applications. J. Gyulai discussed source operation and new possible applications in this area.

\section{New Implantation Equipment and System Techniques}

This session followed traditional conference subjects of equipment design and system techniques. However, new equipment with high current, high energy, and high productivity designs are still being actively developed in many companies. C. McKenna (Varian/Extrion), K. Matsuda (Nissin Electric), M.E. Mack (Eaton Corporation), J. O'Conner (Genus/Ionex), D.W. Berrian (ASM Ion Implantat), J. Fujiyama (ULVAC), and R. Koudijs (High Voltage Engineering Europa) presented their new implantation equipment. Contamination in

Editor's Note: IIT'88 was one of several major materials meetings held in Asia recently, including the MRS International Meeting on Advanced Materials, the 6th International Conference on Ion Beam Modification of Materials (IBMM'88), and the JSAPMRS International Conference on Electronic Materials (ICEM'88). For an overview of these meetings, see the September MRS BULLETIN, $p$. $29 \mathrm{ff}$. Summaries of some of the symposia at the MRS International Meeting on Advanced Materials are published elsewhere in this issue. 
implantation has been recently recognized as a serious problem in system design. T.C. Smith (Motorola) discussed this difficult subject.

\section{Applications for New Materials and Devices}

Metal surface treatments by ion implantation were especially emphasized in this session. I.J.R. Baumvol (UFRGS, Brazil), M. Iwaki (Riken), P. Sioshansi (Spire Corp.), J.M. Williams (Oak Ridge National Laboratory), and G.K. Wolf (University of Heidelberg) gave invited talks on surface metallurgy, surface modification of industrial components, and ion beam processing of surgical materials and metal finishing, respectively. These subjects represent active new applications of ion implantation beyond semiconductor applications.

\section{Emerging Processes for VLSI and Advanced Materials}

This session dealt with ion implantation processes for VLSI applications and emerging processes mostly related to ion beam deposition. T. Tokuyama (University of Tsukuba) reviewed the implantation process for small geometry integrated devices. R. Kakoschke (Siemens) and T.O. Sedgwick (IBM) presented recent data on rapid thermal processing. Several emerging processes using different types of ionbeam deposition and their applications to thin film formation were described. Three invited papers focused on ionized cluster beam (ICB) deposition. I. Yamada (Kyoto University) described a unique ICB deposition process using, as an example, the deposition of an almost perfect large single-crystal Al film on a Si substrate. J. Gspann (University of Karlsruhe) introduced the first production and measurement of $100 \%$ ionized, large (100-3,000 atoms/cluster) cluster beams. T. Ina (Mitsubishi) described development and production of ICB systems for large area deposition. J.J. Cuomo (IBM) reviewed ion-beam-assisted deposition and related fundamental phenomena. He also showed results of new material synthesis. Basically this technique is used for film deposition combined with ion-beam bombardment. Therefore, as was discussed in the session on ion sources, ion sources which can produce very low energy beams at high intensity are invaluable. J.E. Greene (University of Illinois) reviewed low energy ion-beam interaction with surfaces during thin film formation. He tried to systematize and clarify these interactions, which, in contrast to the widely used ion implantation, are complicated and involve many un- known phenomena. $G$. Thompson (Commonwealth Scientific) described several types of commercially available ionassisted deposition equipment developed after many years of his pioneering effort from an industrial perspective. Diamond film deposition is one interesting way to utilize the effect of ions. A. Hiraki (Osaka University) presented results of large-area diamond-like film deposition by a magnetomicrowave plasma technique.

\section{Special Topics}

Reflecting recent important applications was a discussion of $\mathrm{MeV}$ ion implantation and implantation into superconductors. A.D. Marwick(IBM), A.E. White (Bell Laboratories), and $O$. Meyer (Kernforschungszentrum Karlsruhe) gave invited talks on implantation in high Tc superconductors. S. Yasunage (Mitsubishi) commented on high Tc superconductor film deposition with improved crystal structure by ICB. A. Polman (FOM-Institute) talked about a $\mathrm{MeV}$ facility for materials research which was combined with deposition, backscattering, and other diagnostic equipment. N.W. Cheung (University of California, Berkeley) gave an interesting talk on high energy ion implantation for device applications.

The success of this conference can be credited to the cooperation of participants, the members of conference committees, generous donations from over a dozen allied companies in ion implantation technology, and grants from the Commemorative Association for the Japan World Exposition, the Foundation for the Promotion of Ion Engineering, Japan and the $\mathrm{Ni}$ poon Itagarasu Zairyokogaku Jyoseikai. The next conference in this series will be held in Surrey, England in early June 1990.

Isao Yamada Kyoto University Japan

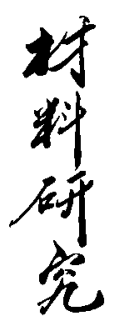

\section{toltatx CVD GASES $100 \%$ GC / MS Analysis!}

\author{
Voltaix, specialists in
} the custom packaging of CVD gases offers: silane, disilane, trisilane; germane, digermane; phosphine, diborane; and gas mixtures.

\section{-ALSO- \\ $100 \%$ GC/MS Analysis}

If you have concerns about the safety and consistency of your CVD gas mixtures, you may want to learn more about our GC/MS analysis capabilities.

\section{Purest Silanes, Germanes, Dopants}

Our strategy is simple: We make or purchase the highest purity gases available, purify using our proprietary methods where required, mix by weight, package into passivated cylinders, and QC the whole process by GC/MS.

\section{Cylinder Valve Choices- for Quality \& Safety}

Voltaix was the first specialty gas supplier to offer the option of VCR outlets on the cylinder valve. These connections are universally respected for their ease of sealing and leak-free performance, and provide a welcome alternative to the conventional CGA outlets. Voltaix also offers various pneumatically controlled cylinder valves which lend themselves to automated, fail-safe gas supply systems.

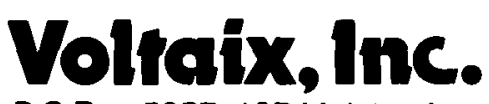

P.O.Box 5357, 197 Meister Ave.

N. Branch, New Jersey 08876

Telephone: (201) 231-9060

Telex: 9102500134 VoltaixUQ 